\title{
As características do biogás e avaliação de substituição de combustíveis
}

\section{The characteristics of biogas and evaluation of fuel substitution}

Me. Eng. João Carlos Christmann Zank ${ }^{2}$ Mestre em Gestão e Sustentabilidade Diretor de Engenharia - ENERMAC joaozank@gmail.com

Esp. Enga. Larissa Schmoeller Brandt ${ }^{3}$ Especialista em Tecnologias da Cadeia Produtiva do Biogás

Enga. Mecânica - ClBiogás larissa.s@cibiogas.org

(iD)

Profa. Dra. Renata Camacho Bezerra ${ }^{1}$ Doutora em Educação Professora Adjunta TIDE - UNIOESTE renatacamachobezerra@gmail.com

Profa. Dra. Eliane Nascimento Pereira ${ }^{1}$ Doutora em Políticas Públicas e Formação

Humana

Professora Titular - UNIOESTE eliane.nascimentop@gmail.com

${ }^{1}$ UNIOESTE - Universidade Estadual do Oeste do Paraná, Parque Tecnológico Itaipu. Av. Tancredo Neves, 6731, CEP 85867-900 Campus Foz do Iguaçu, Paraná, Brasil.

${ }^{2}$ ENERMAC - Soluções com Energia Av. Estados Unidos, 548, Pacaembu, CEP 85816-390 Cascavel, Paraná, Brasil

\footnotetext{
${ }^{3}$ ClBiogás - Centro Internacional de Energias Renováveis - Biogás.Parque Tecnológico Itaipu, Av. Tancredo Neves, 6731, CEP 85867-900 Edifício do Saber, Sala 11 Foz do Iguaçu, Paraná, Brasil
}

\begin{abstract}
Resumo
A evolução das tecnologias e da legislação Brasileira em relação as energias renováveis, em especial solar e biogás, favoreceu o aumento no número de projetos e potência instalada nos últimos 5 anos. O conhecimento sobre as características do biogás é fundamental para realizar estimativas corretas durante a elaboração de projetos, dimensionamento de equipamentos e estudos de viabilidade técnica e financeira, bem como, analisar a intercambialidade entre combustíveis. Sendo que, a apresentação de características como densidade, poder calorífico e fator de compressibilidade, utilizando a ABNT NBR 15.213 de 2008 e informações presentes na literatura, são objetivos deste trabalho. O principal resultado apresentado é a possibilidade de intercambialidade do biogás com o gás natural.
\end{abstract}

Palavras chave: Energias renováveis. Biogás. Fator de compressibilidade e Lei dos Gases Ideais (Equação Clapeyron).

\begin{abstract}
The evolution of Brazilian technologies and legislation in relation to renewable energies, especially solar and biogas, has favored an increase in the number of projects and installed capacity in the last 5 years. Knowledge about the characteristics of biogas is essential to make accurate estimates during project design, and technical and financial feasibility studies, as well as to analyze the interchangeability between fuels. The presentation of characteristics such as density, calorific value and compressibility factor, using ABNT NBR 15.213 of 2008 and the information presented in the literature, are objectives of this work. The main result is the possibility an interchangeability of biogas with natural gas.
\end{abstract}

Keywords: Renewable energy. Biogas. Compressibility factor and Ideal Gas Law (Clapeyron Equation).

\section{Introdução}


O planejamento energético de expansão é baseado nas informações dos planos decenais nacionais publicados pela Empresa de Pesquisa Energética [EPE] e o Ministério de Minas e Energia [MME], isso a mais de 30 anos. Visto que as concessionárias eram estatais, este servia de subsídio para investimentos e o próprio planejamento da expansão. Neste contexto, com a "desestatização" e evolução do setor elétrico, tanto na questão comercial como técnica, e a incorporação de novas fontes à matriz energética nacional, a partir de 2007 a abrangência do estudo foi ampliada, incorporando a expansão de demanda e oferta de diversos energéticos, inclusive fontes renováveis (MME \& EPE, 2017).

No Plano Decenal de Expansão de Energia [PDE] 2017-2026, é preconizado que a participação das energias renováveis no balanço energético atinja o patamar de $48 \%$ ao final do horizonte decenal de planejamento. Na energia elétrica, este patamar alcançará 87\%. Da expansão esperada, 11,8 GW estarão associados a energia eólica e $7 \mathrm{GW}$ à solar-fotovoltaica, configurados como parques de geração conectados à rede básica para transmissão de energia elétrica. (MME \& EPE, 2017).

No Brasil, a modalidade de geração distribuída foi regulamentada em 2012 pela Agência Nacional de Energia Elétrica [ANEEL] por meio da Resolução Normativa [REN] n482, que instituiu o modelo de compensação no país (ANEEL, 2012). Com a publicação da REN no687 (ANEEL, 2015), o regulamento foi aprimorado, de modo a tornar o processo de conexão mais célere e ampliar o acesso à geração distribuída para um número maior de unidades consumidoras. Atualmente, a resolução permite a conexão de geradores com até $5 \mathrm{MW}$ na rede de distribuição, a partir de fontes renováveis de energia ou cogeração qualificada (MME \& EPE, 2017).

Com a REN 482/2012 (ANEEL, 2012) a geração própria teve seu início, e começou a se popularizar. Em 2016 houve crescimento em mais de quatro vezes no número de instalações, terminando o ano com $81 \mathrm{MW}$ instalados, distribuídos em 7,7 mil unidades (ANEEL, 2017). Apesar do crescimento recente, essa modalidade ainda possui um grande potencial inexplorado no Brasil, havendo espaço para se desenvolver muito mais na próxima década.

Dentre as tecnologias de geração distribuída de pequeno porte, destaca-se a baseada no aproveitamento solar fotovoltaico. Essa tecnologia se apresenta com maior potencial de penetração no horizonte decenal, em razão da sua modularidade e custo decrescente.

Contudo, considerando o exposto no relatório da Food and Agriculture Organizations of United Nations, Organização das Nações Unidas para Alimento e Agricultura [FAO] e Organization for Economic Cooperation and Development Organização para Cooperação e Desenvolvimento Econômico - OECD em 2018, o Brasil caminha para tornar-se líder mundial em produção de soja, milho, biocombustível e proteína animal. O relatório considera que a expansão da área agricultável e 
aumento da eficiência para produção agrícola sejam os principais motivos para tal indicação nos próximos 10 anos.

No contexto de expansão da produção de proteína animal e biocombustível, associa-se o crescimento da demanda energética, visto a utilização de processos automatizados nestas cadeias produtivas, buscando eficiência e ganho de escala na produção. Com este crescimento, a produção de resíduos orgânicos, como dejetos animais e rejeitos de processos produtivos será elevada e proporcional.

Conforme definido por (Budzianowski et al., 2017), o biogás é um combustível renovável e sustentável, derivado da digestão anaeróbia da biomassa e elegível para substituição do gás natural. Dessa forma, o saneamento ambiental associado à produção de energia é uma saída sustentável para apoiar esta evolução na produção sendo que, o conhecimento sobre projetos e a escolha correta de equipamentos para uso energético do biogás são cruciais para que esta fonte alcance o potencial esperado.

Considerando as informações apresentadas por FAO e OECD (2018), associados às do MME e EPE (2017), percebe-se que as energias renováveis, e neste contexto o biogás, terão papel estratégico no desenvolvimento da capacidade produtiva do Brasil.

A equivalência energética do biogás com outros combustíveis, a adequação de equipamentos que utilizam outros combustíveis para operar com biogás, e o projeto de equipamentos que utilizarão o biogás como fonte energética, requerem um profundo conhecimento das características do combustível, para tal, o objetivo deste artigo é apresentar as características do biogás e sua intercambialidade com o gás natural, por meio da equação dos gases ideais. Para isso serão apresentados os valores comumente encontrados na literatura e normas existentes para as características e o equacionamento de gases combustíveis. E, com estas informações apresentar-se-á a hipótese para análise de substituição e intercambialidade entre biogás e gás natural utilizando a equação dos gases ideais de Clapeyron.

\section{Referencial teórico}

O referencial teórico é desenvolvido a partir do objetivo do estudo. A próxima seção trata do equacionamento para o biogás em relação à densidade, para então tratar de poder calorífico e do fator de compressibilidade nas seções seguintes, o que norteia a possibilidade de uso da lei dos gases ideais em cálculos com biogás.

Todas as características do biogás são discutidas considerando as informações obtidas em literatura e na norma ABNT NBR 15.213 de 2008. 


\subsection{Conceito e equacionamento conforme ABNT NBR 15.213:2008}

A norma ABNT NBR15.213 (2008) é um documento que fixa os requisitos exigíveis para calcular o poder calorífico, densidade absoluta, densidade relativa e índice de Wobbe para o gás natural e outros combustíveis gasosos, em várias condições de referência. Sabendo que, o biogás bruto se enquadra como um combustível gasoso, será utilizada essa norma como base para definição e determinação das propriedades relacionadas à energia do biogás.

\subsubsection{Conceito e equacionamento}

Conforme definido na norma ABNT NBR15.213 (2008) a densidade absoluta é a quantidade de massa por unidade de volume do gás a uma dada pressão e temperatura. Essa relação é determinada pelo tamanho, peso dos átomos e tipo de ligação química. Já a densidade relativa, ainda segundo a norma, é a relação entre a densidade absoluta de um gás e a densidade absoluta do ar seco com composição padronizada, nas mesmas condições de temperatura e pressão.

A densidade absoluta de um gás real depende da temperatura T e pressão p, e calcula-se pela Equação (1):

$$
\rho_{(T, p)}=\frac{\rho_{i(T, p)}}{Z_{m i s(T, p)}}
$$

Onde:

$\rho_{(T, p)}$ é a densidade absoluta do gás real;

$\rho_{i(T, p)}$ é a densidade absoluta do gás ideal;

$Z_{m i s(T, p)}$ é o fator de compressibilidade do gás no estado de referência.

Já a densidade absoluta do gás ideal também é dependente da temperatura e pressão, conforme apresenta-se na Equação (2):

$$
\rho_{i(T, p)}=\left(\frac{p}{R . T(K)}\right) \sum_{j=i}^{N}\left(x j . M_{j}\right)
$$

Onde:

$\rho_{i(T, p)}$ é a densidade absoluta do gás ideal;

$T(K)$ é a temperatura absoluta;

$R$ é a constante molar dos gases;

$x j$ é a fração molar do componente j;

$p$ é a pressão absoluta;

$M_{j}$ é a massa molar do componente j. 
A densidade relativa de um gás real a uma dada temperatura e pressão é calculada pela Equação (3):

$$
d_{(T, p)}=d_{i} \frac{Z_{\operatorname{ar}(T, p)}}{Z_{\operatorname{mis}(T, p)}}
$$

Onde:

$d_{(T, p)}$ é a densidade relativa do gás real;

$d_{i}$ é a densidade relativa do gás ideal;

$Z_{a r(T, p)}$ é o fator de compressibilidade do ar seco no estado de referência;

$Z_{m i s(T, p)}$ é o fator de compressibilidade do gás no estado de referência.

O conceito do fator de compressibilidade e o fator de compressibilidade do biogás serão discutidos e equacionados no tópico 5 e 6, respectivamente. Para o ar, valores comumente utilizados são:

$\mathrm{T}=0^{\circ} \mathrm{C}, \mathrm{P}=1 \quad Z_{\text {ar }(273,15 K, 101,325 \mathrm{kPa})}=0,99941$

atm

$\mathrm{T}=15^{\circ} \mathrm{C}, \quad Z_{\operatorname{ar}(288,15 \mathrm{~K}, 101,325 \mathrm{kPa})}=0,99958$

$\mathrm{P}=1 \mathrm{~atm}$

$\mathrm{T}=20^{\circ} \mathrm{C}, \quad Z_{\text {ar }(293,15 K, 101,325 \mathrm{kPa})}=0,99963$

$\mathrm{P}=1 \mathrm{~atm}$

E a densidade relativa do gás ideal é independente de qualquer estado de referência, sendo calculada pela Equação (4):

$$
d_{i}=\sum_{j=1}^{N} x_{j} \cdot \frac{M_{j}}{M_{a r}}
$$

Onde:

$d_{i}$ é a densidade relativa do gás ideal;

$N$ é o número total de componentes;

$x_{j}$ é a fração molar do componente j;

$M_{j}$ é a massa molar do componente j;

$M_{a r}$ é a massa molar do ar de composição padrão. 


\subsection{Densidade do biogás}

O biogás é um gás incolor e em alguns casos inodoro, dependendo da composição. A composição típica da mistura gasosa que forma o biogás, é apresentada na Tabela 1.

Tabela 1 - Composição química do biogás

\begin{tabular}{|c|c|}
\hline Composto & $\begin{array}{c}\text { Porcentagem na } \\
\text { Mistura Gasosa (\%) }\end{array}$ \\
\hline Metano $\left(\mathrm{CH}_{4}\right)$ & 50 a 75 \\
\hline Dióxido de Carbono $\left(\mathrm{CO}_{2}\right)$ & 25 a 40 \\
\hline Hidrogênio $\left(\mathrm{H}_{2}\right)$ & 1 a 3 \\
\hline Azoto $\left(\mathrm{N}_{2}\right)$ & 0.5 a 2.5 \\
\hline Oxigênio $\left(\mathrm{O}_{2}\right)$ & 0.1 a 1 \\
\hline Gás Sulfídrico $\left(\mathrm{H}_{2} \mathrm{~S}\right)$ & 0.1 a 0.5 \\
\hline Amoníaco $\left(\mathrm{NH}_{3}\right)$ & 0.1 a 0.5 \\
\hline Monóxido de Carbono $(\mathrm{CO})$ & 0 a 0.1 \\
\hline Água $\left(\mathrm{H}_{2} \mathrm{O}\right)$ & Variável \\
\hline
\end{tabular}

Fonte: Adaptado de (Zachow, 2000).

A densidade do biogás, quando é conhecida sua composição, pode ser determinada pelos equacionamentos apresentados anteriormente e previstos em norma técnica. Ou ainda, pode-se utilizar valores padronizados já fundamentados por diversas bibliografias, como será apresentado nas Tabelas 2 e 3. O biogás é um gás leve e de fraca densidade. Mais leve do que o ar, essa fraca densidade faz com que ele ocupe um volume significativo e que a sua liquefação seja mais difícil, o que implica em desvantagens em termos de transporte, armazenamento e utilização conforme Tabela 2, (lannicelli, 2008).

Tabela 2 - Densidade do biogás conforme a concentração de metano

\begin{tabular}{|c|c|}
\hline Composição química & Densidade \\
\hline $10 \% \mathrm{CH}_{4}$ e $90 \% \mathrm{CO}_{2}$ & 1,8393 \\
\hline $40 \% \mathrm{CH}_{4}$ e $60 \% \mathrm{CO}_{2}$ & 1,4600 \\
\hline $60 \% \mathrm{CH}_{4}$ e $40 \% \mathrm{CO}_{2}$ & 1,2143 \\
\hline $65 \% \mathrm{CH}_{4}$ e $35 \% \mathrm{CO}_{2}$ & 1,1518 \\
\hline $75 \% \mathrm{CH}_{4}$ e $25 \% \mathrm{CO}_{2}$ & 1,0268 \\
\hline $95 \% \mathrm{CH}_{4}$ e $05 \% \mathrm{CO}_{2}$ & 0,7768 \\
\hline $99 \% \mathrm{CH}_{4}$ e $01 \% \mathrm{CO}_{2}$ & 0,7268 \\
\hline
\end{tabular}

Fonte: (lannicelli, 2008).

Fachagentur Nachwachsende Rohstoffe, do alemão, Agência de Recursos Renováveis [FNR] (2013) diz que o biogás apresenta uma densidade de $1,2 \mathrm{~kg} / \mathrm{m}^{3}$. Já (Seadi et al., 2008), considera o biogás com $50 \%$ de metano e densidade de $1,22 \mathrm{~kg} / \mathrm{m}^{3}$. O autor (Lemos, 2013), apresenta a densidade 
relativa de biogás proveniente de esgoto com $67,5 \%$ de metano igual a $0,8148 \mathrm{~m}^{3} / \mathrm{kg}$, ou seja, uma densidade igual à $1,2273 \mathrm{~kg} / \mathrm{m}^{3}$. E, temos o autor (Okamura, 2013) que faz uma comparação entre a densidade do biogás proveniente de aterros sanitário, no qual resulta $45 \%$ de metano e de biogás proveniente de biodigestores com $65 \%$ de metano, sendo de $1,3 \mathrm{~kg} / \mathrm{m}^{3}$ e $1,1 \mathrm{~kg} / \mathrm{m}^{3}$ respectivamente.

Considerando as bibliografias consultadas/pesquisadas, pode-se elaborar a Tabela 3, que apresenta a relação encontrada pelos autores entre a densidade e a porcentagem de Metano no biogás.

Tabela 3 - Valores de densidade em relação ao percentual de metano no biogás, referenciados com as pesquisas

\begin{tabular}{|c|c|c|}
\hline Autor & Porcentagem de $\mathrm{CH} 4$ & Densidade $[\mathrm{kg} / \mathrm{m} 3]$ \\
\hline Okamura (2013) & $45 \%$ & 1,3 \\
\hline Seadi et al. (2008) & $50 \%$ & 1,22 \\
\hline lannicelli (2008) & $60 \%$ & 1,2143 \\
\hline Iannicelli (2008) & $65 \%$ & 1,1518 \\
\hline Okamura (2013) & $65 \%$ & 1,1 \\
\hline Lemos (2013) & $67,5 \%$ & 1,2273 \\
\hline FNR (2013) & - & 1.2 \\
\hline Média & 58,75 & 1,2022 \\
\hline
\end{tabular}

Fonte: Adaptado pelo Autor.

Para definição do valor de densidade padrão, utilizando o método do ajuste linear, gerou-se duas funções, que relacionam a porcentagem de metano no biogás e a densidade. Na Equação (5), utiliza-se os valores da Tabela 2 para determinar os coeficientes da Função Densidade (FD), sendo que os valores dessa tabela são apresentados apenas por (lannicelli, 2008).

$$
F D_{1}=1,962586593-\left(C H_{4} * 0,01248267152\right)
$$

Já na Equação (6), os coeficientes da FD2 são definidos pelos valores da Tabela 3, os quais são apresentados por vários autores diferentes.

$$
F D_{2}=1,518997778-\left(C_{4} * 5,4124444 * 10^{-3}\right)
$$

A Tabela 4 foi elaborada por meio das funções anteriores e os valores encontrados foram então comparados: 
Tabela 4 - Comparação das funções densidade

\begin{tabular}{|c|c|c|c|}
\hline CH4 & FD1 & FD2 & Diferença \\
\hline $40 \%$ & 1,4632797322 & 1,302500018 & 0,160779714 \\
\hline $50 \%$ & 1,338453017 & 1,248375578 & 0,090077439 \\
\hline $60 \%$ & 1,2136263018 & 1,194251138 & 0,019375164 \\
\hline $70 \%$ & 1,0887995866 & 1,140126698 & $-0,051327111$ \\
\hline $80 \%$ & 0,9639728714 & 1,086002258 & $-0,122029387$ \\
\hline $90 \%$ & 0,8391461562 & 1,031877818 & $-0,192731662$ \\
\hline $99 \%$ & 0,714319441 & 0,983165822 & $-0,268846381$ \\
\hline
\end{tabular}

Fonte: Próprio Autor.

Analisando a Tabela 4, pode-se observar que o valor que apresentou a menor diferença entre as duas funções foi para biogás com $60 \%$ de metano, sendo este valor comum, conforme apresentado nas literaturas da Tabela 3 e próximo da média. Dessa forma, o valor de densidade do biogás a ser considerado como base padrão deve ser de $1,2039 \mathrm{~kg} / \mathrm{m}^{3}$, que é o valor médio entre os resultados das duas funções.

\subsection{Poder calorífico}

O poder calorífico é a propriedade relacionada à quantidade de calor liberada na combustão completa da unidade de massa (ou volume) de um combustível, sendo os fumos da combustão resfriados até a temperatura do combustível $\left(18\right.$ ou $\left.25^{\circ} \mathrm{C}\right)$. Dessa forma, o poder calorífico de um combustível representa a quantidade de energia do material, independentemente do fato de ser ou não realizada a combustão.

A ABNT NBR 15.213 (2008), define o Poder Calorífico Superior e Inferior como:

Poder Calorífico Superior (PCS): quantidade de energia liberada na forma de calor, na combustão completa de uma quantidade definida de gás com o ar, à pressão constante e com todos os produtos de combustão retornando à temperatura e pressão iniciais dos reagentes, onde toda a água formada pela reação encontra-se na forma líquida.

Poder Calorífico Inferior (PCI): quantidade de energia liberada na forma de calor, na combustão completa de uma quantidade definida de gás com o ar, à pressão constante e com todos os produtos de combustão retornando à temperatura e pressão iniciais da reagente, onde toda a água formada pela reação encontra-se na forma gasosa. (ABNT NBR 15213, 2008, p. 4).

Na Tabela 5, apresenta-se as equivalências de valores para conversão de algumas unidades relacionadas ao $\mathrm{PCl}$ para Joule, que é a unidade do sistema internacional.

Tabela 5 - Conversão de unidadesPCI

\begin{tabular}{|c|c|}
\hline $1 \mathrm{Wh}$ & $3600 \mathrm{~J}$ \\
\hline $1 \mathrm{cal}$ & $4,186 \mathrm{~J}$ \\
\hline $1 \mathrm{~W}$ & $1 \mathrm{~J} / \mathrm{s}$ \\
\hline
\end{tabular}

Fonte: Próprio Autor. 
O poder calorífico pode ser calculado em base molar, mássica e volumétrica, sendo que para os cálculos de energia térmica disponível é utilizado a base mássica ou volumétrica e apenas essas duas serão apresentadas neste artigo. Na norma ABNT NBR 15.213 (2008), o poder calorífico para gases reais em base mássica é numericamente igual ao poder calorífico correspondente para gases ideias, assim serão apresentados apenas os equacionamentos para os gases reais.

O poder calorífico para um gás real em base mássica em uma temperatura T1 (ver Tabela 5: Valores do poder calorífico para componentes dos gases combustíveis sob diferentes condições de referência de combustão e de medição para gás ideal em base volumétrica - ABNT NBR 15.213-2008) é calculada pela Equação (7):

$$
\widehat{P C}=\sum_{j=1}^{N}\left(x_{j} \cdot \frac{M_{j}}{M} \cdot P \hat{C} j\right)
$$

Onde:

$\widehat{P C}$ é o poder calorífico, superior ou inferior, ideal em base mássica;

$P \hat{C} j$ é o poder calorífico, superior ou inferior, em base mássica do componente j;

$x_{j}$ é a fração molar do componente j;

$M$ é a massa molar da mistura, calculada pela Equação (8):

$$
M=\sum_{j=1}^{N} x_{j} . M_{j}
$$

$M_{j}$ é a massa molar do componente j (Tabela B.1 - ABNT NBR 15.213-2008).

O poder calorífico superior e inferior para uma mistura de gases ideais em base volumétrica na temperatura de combustão T1, medido na temperatura T2 e pressão p2, é calculada pela Equação (9):

$$
\tilde{P} C_{i\left[T_{1}(K), V\left(T_{2}(K), p_{2}\right)\right]}=\bar{P} C_{i\left[T_{1}(K)\right]} \cdot \frac{p_{2}}{R \cdot T_{2}(K)}
$$

Onde:

$\tilde{P} C_{i}$ é o poder calorífico, superior ou inferior, do gás ideal em base volumétrica na temperatura de combustão T1, medido na temperatura T2 e pressão p2;

$\bar{P} C_{i}$ é o poder calorífico, superior ou inferior, do gás ideal em base molar (Tabela B.3 - ABNT NBR 15.213-2008);

P2 é a pressão na condição de medição; 
T2(K) é a temperatura absoluta na condição de medição;

R é a constante molar dos gases. (10):

O cálculo do poder calorífico em base volumétrica para gases reais é calculado pela Equação

$$
\tilde{P} C_{\left[T_{1}(K), V\left(T_{2}(K), p_{2}\right)\right]}=\frac{\bar{P} C_{i\left[T_{1}(K), V(T 2(K), p 2]\right.}}{Z_{(T, p)}}
$$

Onde:

$\widetilde{P} C$ é o poder calorífico, superior ou inferior, do gás real em base volumétrica;

$\tilde{P} C_{i}$ é o poder calorífico, superior ou inferior, do gás ideal em base volumétrica;

$Z_{(T, p)}$ é o fator de compressibilidade do gás.

\subsection{Poder calorífico do biogás}

O poder calorífico do biogás apresentará variação conforme a sua composição e concentração de diferentes gases, e este pode ser calculado pelos equacionamentos anteriores, entretanto, em casos onde a composição exata não é conhecida, podem ser utilizados valores de referência.

Na Tabela 6, apresenta-se os valores de poder calorífico inferior em diferentes referenciais bibliográficos.

Tabela 6 - Valores de PCI para o biogás encontrados na literatura

\begin{tabular}{|c|c|c|c|}
\hline Bibliografia & Valor & Unidade & $\begin{array}{c}\text { Padronização de } \\
\text { Unidades }\end{array}$ \\
\hline FNR (2013) & 6 & $\mathrm{kWh} / \mathrm{m}^{3} . \mathrm{h}$ & $21093,75 \mathrm{~kJ} / \mathrm{kg}^{1}$ \\
\hline $\begin{array}{c}\text { Santos } \\
(2004)\end{array}$ & $\begin{array}{c}5,339(65 \% \mathrm{de} \\
\text { metano) }\end{array}$ & $\mathrm{kcal} / \mathrm{m}^{3}$ & $21814,82 \mathrm{~kJ} / \mathrm{kg}^{2}$ \\
\hline $\begin{array}{c}\text { Souza } \\
\text { (2006) }\end{array}$ & $\begin{array}{c}19250(63 \% \mathrm{de} \\
\text { metano) } \\
\begin{array}{c}\text { (1988) e } \\
\text { Çengel e } \\
\text { Boles (2008) }\end{array}\end{array}$ & $\mathrm{kJ} / \mathrm{kg}$ & $19250 \mathrm{~kJ} / \mathrm{kg}$ \\
\hline Média & 6,1 & $\mathrm{kWh} / \mathrm{m}^{3}$ & $21445,31 \mathrm{~kJ} / \mathrm{kg} . \mathrm{s}^{3}$ \\
\hline
\end{tabular}

Fonte: Adaptado pelo Autor.

\footnotetext{
${ }^{1}$ Este valor foi obtido dividindo-se o valor do $\mathrm{PCl}$ dividido pela densidade do biogás $\left(1,024 \mathrm{Kg} / \mathrm{m}^{3}\right)$

${ }^{2}$ Valor obtido multiplicando o valor do $\mathrm{PCl}$ em cal por 4186 para conversão para Joule e este valor dividido pela densidade do Biogás $\left(1,024 \mathrm{Kg} / \mathrm{m}^{3}\right)$

${ }^{3}$ Valor obtido pela divisão do $\mathrm{PCl}$ em $\mathrm{kW} / \mathrm{m}^{3}$ pela densidade do Biogás $\left(1,024 \mathrm{Kg} / \mathrm{m}^{3}\right)$
} 
Na Tabela 7, apresenta-se a variação no valor do PCl conforme a porcentagem de Metano $\left(\mathrm{CH}_{4}\right)$ no biogás em conformidade à (Avellar, 2001).

Tabela 7 - Composição Química e PCl

\begin{tabular}{|c|c|c|}
\hline $\begin{array}{c}\text { Composição } \\
\text { química }\end{array}$ & $\begin{array}{c}\text { Poder Calorífico } \\
\text { (kcal/kg) }\end{array}$ & Poder Calorífico (kJ/kg) \\
\hline $10 \% \mathrm{CH}_{4}$ e $90 \% \mathrm{CO}_{2}$ & 465,43 & 1948,29 \\
\hline $40 \% \mathrm{CH}_{4}$ e $60 \% \mathrm{CO}_{2}$ & 2333,85 & 9769,50 \\
\hline $60 \% \mathrm{CH}_{4}$ e $40 \% \mathrm{CO}_{2}$ & 4229,98 & 17706,70 \\
\hline $65 \% \mathrm{CH}_{4}$ e $35 \% \mathrm{CO}_{2}$ & 4831,14 & 20223,15 \\
\hline $75 \% \mathrm{CH}_{4}$ e $25 \% \mathrm{CO}_{2}$ & 6253,01 & 26175,10 \\
\hline $95 \% \mathrm{CH}_{4}$ e $05 \% \mathrm{CO}_{2}$ & 10469,60 & 43825,75 \\
\hline $99 \% \mathrm{CH}_{4}$ e $01 \% \mathrm{CO}_{2}$ & 11661,02 & 48814,03 \\
\hline
\end{tabular}

Fonte: (Avellar, 2001).

\subsection{Fator de compressibilidade}

O fator de compressibilidade de um gás é o volume real da massa desse gás, a uma dada temperatura e pressão, dividida pelo seu volume, nas mesmas condições, calculado a partir da equação do gás ideal (ABNT NBR 15.213, 2008).

O fator de compressibilidade pode ser calculado pela Equação (11):

$$
Z_{(T, p)}=1-\left[\sum_{j=1}^{N}\left(x_{j} \cdot \sqrt{b_{j}}\right)\right]^{2}
$$

Onde:

$Z_{(T, p)}$ é o fator de compressibilidade do gás, nas condições de referência de temperatura e pressão;

$x_{j}$ é a fração molar do componente j;

N é o número total de componentes;

$\sqrt{b_{j}}$ é o fator de adição do componente j (ver Tabela B.2 - ABNT NBR 15.213-2008).

\subsection{Fator de compressibilidade biogás}

O fator de compressibilidade do biogás irá variar conforme a sua composição, como pode ser visto na Tabela 8, a qual foi construída utilizando a Equação (11). 
Tabela 8 - Variação do fator de compressibilidade do biogás $\left(20^{\circ} \mathrm{C}, 1 \mathrm{~atm}\right)$

\begin{tabular}{|c|c|c|}
\hline \multicolumn{2}{|c|}{ Constituintes } & \multirow{2}{*}{ Fator de Compressibilidade } \\
\hline $\mathrm{CH}_{4}$ & $\mathrm{CO}_{2}$ & 0,9958 \\
\hline $30 \%$ & $70 \%$ & 0,9962 \\
\hline $40 \%$ & $60 \%$ & 0,9965 \\
\hline $50 \%$ & $50 \%$ & 0,9969 \\
\hline $60 \%$ & $40 \%$ & 0,9972 \\
\hline $70 \%$ & $30 \%$ & 0,9975 \\
\hline $80 \%$ & $20 \%$ & 0,9978 \\
\hline $90 \%$ & $10 \%$ & 0,9980 \\
\hline $97 \%$ & $3 \%$ & 0,9970 \\
\hline \multicolumn{2}{|c|}{ Média } & 0,00077 \\
\hline \multicolumn{2}{|c|}{ Desvio padrão } \\
\hline
\end{tabular}

Fonte: Próprio Autor.

Pode-se observar que na variação de 30 a $97 \%$ de metano no biogás o fator de compressibilidade variou apenas 0,00077 na média. Pode-se concluir que, em condições de pressão e temperatura normais $\left(\mathrm{T}=20^{\circ} \mathrm{C}\right.$ e $\left.\mathrm{P}=1 \mathrm{~atm}\right)$, tanto para o biogás, quanto para o biometano, pode-se utilizar o valor médio de 0,9970 garantindo resultados coerente e confiáveis.

\section{Lei dos gases reais e ideais}

A observação das características do biogás apresentada na seção anterior, quando balizada em relação as variáveis termodinâmicas descritas nas leis dos gases reais e ideais, permite a comparação entre gases combustíveis. A lei dos gases reais considera o ajuste da equação Clapeyron como descrito por (Sabin, Prestes, Martins, Adaime e Zanella, 2011) pelo fator de compressibilidade do gás. Sendo a Equação (12), representativa para este conceito.

$$
P . V=Z_{(T, p)} \cdot n \cdot R \cdot T
$$

Onde:

$P$ é a pressão do gás, $\mathrm{kgf} / \mathrm{cm}^{2}$;

$V$ é o volume ocupado pelo gás, $\mathrm{m}^{3}$;

$Z_{(T, p)}$ é o fator de compressibilidade;

$n$ é o número de moles do gás, $\mathrm{kg}$ mol;

$R$ é a constante universal dos gases, 0,0848 kgf;

$T$ é a temperatura absoluta do gás na escala kelvin;

O fator de compressibilidade do biogás apresentado, $\left(Z_{(T, p)}=0,9970\right)$ próximo de 1 (um), indica a possibilidade de utilização da lei dos gases ideais, sem prejuízos significativos quando da 
substituição hipotética entre gases combustíveis que também possuam fator de compressibilidade unitário, dentre eles o gás natural (BEGGS, 1984).

Quanto a lei dos gases ideais, conforme descrito por (Sabin et al, 2011),

a lei de Charles estabelece que, sob pressão constante, o volume de uma quantidade constante de gás aumenta proporcionalmente com a temperatura. A lei de Boyle-Mariotte estabelece que, sob transformação isotérmica, o produto entre pressão e volume é constante; e Gay-Lussac afirma que, sob um volume e quantidade de gás constantes, a pressão é diretamente proporcional à temperatura. Por fim, Avogadro acrescenta que o aumento do número de partículas implica no aumento do número de colisões e um igual número de partículas para gases diferentes implica em um igual número de colisões. Assim, as leis de Charles, Boyle-Mariotte Gay-Lussac e Avogadro podem ser expressas pela equação de estado de Clapeyron. (Sabin et al, 2011, p.415).

A Equação que reúne as leis descritas acima é a 13.

$$
P . V=n \cdot R \cdot T
$$

Onde:

$P$ é a pressão do gás, $\mathrm{kgf} / \mathrm{cm}^{2}$;

$V$ é o volume ocupado pelo gás, $\mathrm{m}^{3}$;

$n$ é o número de moles do gás, kg mol;

$R$ é a constante universal dos gases, 0,0848 kgf;

$T$ é a temperatura absoluta do gás na escala kelvin;

Considerando que o biogás obedece a Lei dos Gases Ideais, há disponível um rol de equações para dimensionamento de vasos de pressão, utilizados em usa maioria para gás natural, e que pode ser utilizado no dimensionamento de tubulações, queimadores e gasômetros para biogás, sendo possível ainda a calibração de equipamentos de medição e monitoramento, visto que equipamentos utilizados para medir vazão e pressão com gás natural podem ser utilizados e aferidos para biogás com grande precisão.

\section{Conclusão}

A possibilidade de comparar gases sob uma mesma base ou método, é útil quando falamos da substituição de combustíveis e insumos energéticos, seja em unidades geradoras, caldeiras ou mesmo fogões e veículos. Permite-se neste contexto, comparar equipamentos em relação a sua eficiência para produção de energia elétrica, térmica e veicular, bem como, realizar o dimensionamento dos equipamentos e seu estudo de viabilidade para aplicação e substituição de combustíveis.

Conforme apresentado em outros trabalhos, (Silva, 2013; Felippe, 2009; Halmeman et al., 2014; Budzianowski et al., 2017) o uso do biogás como substituto do gás natural é promissor, contudo, 
o biogás gerado por meio da digestão anaeróbica possui outras características as serem consideradas, como indicado por (Budzianowski et. al., 2017), o biogás gerado está naturalmente em baixa pressão, possui baixa gravidade específica e alto volume específico, sendo desafiador seu armazenamento com fins energéticos, pois sua proporção de Dióxido de Carbono, reduz seu poder calorífico, velocidade de chama e limites de inflamabilidade, se comparado ao gás natural. Apesar destas dificuldades, seu uso como fonte renovável de energia, por muitas vezes substituindo o gás natural é reconhecido como estratégico na matriz energética dos países (FNR, 2013; Santos et al., 2015).

Considerando os valores apresentados na Tabela 1, para composição química do biogás (Zachow, 2000), e a conclusão de que o biogás permanece com seu fator de compressibilidade muito próximo à um (1), desde concentrações de 30\% até 97\% de Metano, comprovou-se a hipótese da possibilidade de intercambialidade do biogás com o gás natural com a utilização da Lei dos Gases Ideais. A relevância desta comprovação é útil no dimensionamento de equipamentos para uso energético e vasos de pressão, como: tubos, conexões, válvulas de manobra, reservatórios e máquinas para compressão e transporte do biogás, visto o aproveitamento da literatura e equações desenvolvidas para gás natural.

\section{Referências}

ABNT NBR 15213:2008. Gás Natural - Cálculo de propriedades físico-químicas a partir da composição Devido. 2008. ABNT.

ANEEL. Agência Nacional de Energia Elétrica. Resolução Normativa no482. 2012. Disponível em: http://www2.aneel.gov.br/cedoc/ren2012482.pdf. Acesso em: 29 set. 2018.

ANEEL. Agência Nacional de Energia Elétrica. Resolução Normativa no687. 2015. Disponível em: http://www2.aneel.gov.br/cedoc/ren2015687.pdf. Acesso em: 29 set.2018.

ANEEL. Agência Nacional de Energia Elétrica. Banco de Informações da Geração (BIG). 2017 Disponível em: http://www2.aneel.gov.br/aplicacoes/capacidadebrasil/capacidadebrasil.cfm. Acesso em: 17 dez. 2017.

Avellar, L. H. N. (2001) A valorização dos subprodutos agroindustriais visando a cogeração e a redução da poluição ambiental. Teses de Doutorado - UNESP. Guaratinguetá, SP.

Beegs, H. D. (1984) Gas Production Operations, Tulsa OK: OGCI Publications.

Budzianowski, W. M. et al. (2017) Power Requirements of biogas upgrading by water scrubbing and biomethane compression: Comparative analysis of various plant configurations. Energy Conversion and Management, v. 141, p. 2-19.

Çengel, Y. A.; \& Boles, M. A. (2008) Termodinâmica. 5. ed. São Paulo: McGraw-Hill.

FNR. Ministério da Nutrição Agricultura e Defesa do Consumidor da Alemanha. (BMELV) (Ed.). Guia Prático do Biogás: Geração e Utilização. 5. ed. Gülzow-prüzen: Fachagentur Nachwachsende Rohstoffe E. V. (2013) (FNR). ALEMANHA. P. 236.

Halmeman, M.C.R. et al. (2014) The Deployment of biodigester systems in rural properties. Brazilian Journal of Biosystems Enginnering, v. 8, n. 4, p. 351-360.

Ianniceli, L. A. (2008) Reaproveitamento energético do biogás de uma indústria cervejeira. Taubaté: DEM/UNITAL, Dissertação mestrado.

Lemos, M. V. D. (2013) Uso eficiente de biogás de esgoto em motores geradores. 2013. 59 f. TCC (Graduação) - Curso de Engenharia Mecânica, Universidade Federal do Rio de Janeiro, Rio de 
Janeiro.

MME \& EPE. Ministério de Minas e Energia, Empresa de Pesquisa Energética (2017). Plano Decenal de Expansão de Energia 2026 / Ministério de Minas e Energia. Empresa de Pesquisa Energética. Brasília, DF: MME/EPE.

Mitzlaf, K. V.(1988) Engines for biogas. Eschborn: GTZ.

OECD \& FAO. Food and Agriculture Organizations of United Nations, \& Organização para Cooperação e Desenvolvimento Econômico (2018). OECD-FAO Agricultural Outlook 2018-2027. OECD Publishing, Paris / Food and Agriculture Organization of the United Nations, Rome. Disponível em: https://doi.org/10.1787/agr outlook-2018-en. Acesso em 28 set. 2018.

Okamura, L. A. (2013) Avaliação e melhoria do poder calorífico de biogás proveniente de resíduos sólidos urbanos. 80 f. Dissertação (Mestrado) - Curso de Ciência e Tecnologia Ambiental, Universidade Tecnológica Federal do Paraná, Curitiba. 2013.

Sabin, G. P., Prestes, O. D., Martins, M. L., Adaime, M. B., \& Zanella, R. (2011) Aumento da resposta analítica por meio da otimização do sistema de injeção em cromatografia gasosa empregando a lei dos gases ideais. Química Nova. Vol. 34, No. 3, 414-418.

Santos, J. H. T. (2004) Avaliação de um sistema de aquecimento do Substrato na Biodigestão Anaeróbia de Dejetos Suínos. 2004. 82 f. Tese (Doutorado) - Curso de Engenharia Agrícola, Universidade Federal de Viçosa, Viçosa/MG.

Santos, J.T.S. et al.(2015) Estimativa da viabilidade de produção de biogás a partir do efluente de indústrias de laticínios no estado de Sergipe utilizando modelagem e simulação. Exacta - EP, São Paulo, v. 13, n. 2, p. 229-237.

Seadi, T. (2013) Biogas Handbook. Esbjerg: University of Southern Denmark. Esbjerg.

Silva, A.R.B.(2013) Tratamento de efluentes na indústria de laticínios. 2013. 26 f. Monografia (Engenharia Química) - Universidade Federal de Uberlândia, Uberlândia/MG.

Souza, R. G. (2006) Desempenho do conjunto motogerador adaptado a biogás. 2006. 40 f. Dissertação (Mestrado) - Curso de Engenharia Agrícola, Universidade Federal de Lavras, Lavras/MG.

Zachow, C. R. (2000) Biogás. 2000. 12 f. - DeTEC - Departamento de Tecnologia, UNIJUI Universidade Regional do Noroeste do Estado do Rio Grande do Sul, ljuí/RS.

Zhang, C. et al. (2014) Reviewing the anerobic digestion of food waste for biogas production. Renewable and Sustainable Energy Reviews, v. 38, p.

Recebido em: 23 out. 2018 / Aprovado em: 17 abr. 2019

Para referenciar este texto

American Psychological Association (APA)

Zank, J. C. C., Brandt, L. S., Bezerra, R. C., \& Pereira, E. N. (2020). As características do biogás e avaliação de substituição de combustíveis. Exacta, 18(3), 502-516. https://doi.org/10.5585/ExactaEP.v18n3.10802. 